\title{
Men's Perception of Domestic Violence, Rural Minia, Egypt
}

\author{
Ebtesam Esmail Hassan, Amany Edward Seedhom*, Eman Mohamed Mahfouz \\ Public Health Department, Faculty of Medicine, Minia University, Minia, Egypt \\ Email: *amany_medhat@yahoo.com
}

Received 5 January 2016; accepted 26 February 2016; published 29 February 2016

Copyright (C) 2016 by authors and Scientific Research Publishing Inc.

This work is licensed under the Creative Commons Attribution International License (CC BY). http://creativecommons.org/licenses/by/4.0/

(c) †) Open Access

\section{Abstract}

Background: Domestic violence is an important prevalent, yet hidden and ignored health concern with significant impact on women's health and wellbeing. This research was guided by the belief that men could play a role in preventing domestic violence as the majority of domestic violence is perpetrated by men. Aim: To assess attitudes of men towards domestic violence and factors affecting violence supportive attitude. Methods: A cross-sectional community-based study conducted in a rural area, Minia District, 2015. A systematic random sample was used. An interview-administered questionnaire was used including questions related to violence supportive environments, and opinion of men of causes and existence of domestic violence within families. Gender equity score (GES) was applied. Results: A total of $\mathbf{4 4 0}$ males participated. $57.3 \%$ of the participants reported that domestic violence was sometimes justified and needed in certain cases, and nearly two third $(69 \%)$ of them practiced violence against their wives mostly in the form of physical one (64\%). Small proportion of males reported high support for gender equity (7\%). The study identified reasons for domestic violence, as perceived by men: The commonest was marital disputes (48.9\%), followed by financial problems $(36.4 \%)$ and social and economic disparity between the spouses $(12.7 \%)$. Regarding the effect of violence on families, $30.9 \%$ of males reported that it led to lack of proper education. Conclusion and Recommendations: There is a tendency to describe this community as abusive. There is a need for development of relevant and culturally sensitive domestic violence education/prevention program in rural Egypt.

\section{Keywords}

Domestic Violence, Male Perception, Rural, Minia, Egypt

\footnotetext{
${ }^{*}$ Corresponding author.
} 


\section{Introduction}

Domestic violence is an important prevalent, yet hidden and ignored health concern with significant impact on women's health and wellbeing not just in terms of injury and premature death, but in terms of mental health problems including attempted suicide and self-harm, depression, anxiety, substance abuse, and poor reproductive health. It is a complex and persistent problem with multiple causes. It results from a complex, interconnected ecology of psychological, economic, and sociological factors. Domestic violence is an important social, economic, and health concern that occurs in all ages and socio-economic levels [1].

It can be seen as a global pandemic: Between $15 \%$ and $76 \%$ of women experience it at some point in their lifetime. While reliable statistics are hard to come by, studies estimated that, from a country to another, between $20 \%$ and $50 \%$ of women have experienced physical violence at the hands of an intimate partner or family member [2].

Despite there being numerous, various definitions of domestic violence and an abundance of statistics, ambiguity regarding the true nature of domestic violence is apparent within society and subject to various stereotypical attitudes. Domestic violence is known as domestic abuse, spousal abuse, child abuse or spousal partner violence or family violence [3].

The Federal Bureau of Investigation (FBI) in the United States identified domestic violence as offences against the family and children and described it as "Unlawful violent acts by a family member that threaten the physical, mental, or economic well-being or morals of another family member and that are not classifiable as other offences, such as assault or sex offences" [4].

Domestic violence takes a number of forms. The most common forms are physical and sexual violence, threats, emotional and social abuse and economic deprivation [5].

Domestic violence is a multi-causal social problem and is symptomatic of power relations that are deeply rooted in the social structure which provides space for its existence. There continues to be a high level of tolerance by both men and women of domestic violence. Domestic violence has resulted from the power imbalances that exist between men and women and the inequality that exists within the context of family relationships [6].

The research was guided by the fundamental belief that men can play a positive role in preventing family violence. Indeed, without men’s involvement, efforts to reduce and prevent family violence will fail [7].

Domestic violence has a significant impact on the general health and well-being of women, and is associated with a wide range of health problems [8]. Beyond this, many victims reported that the emotional impact of experiencing domestic violence out-weighs physical injuries [9].

The strongest predictor for holding violence-supportive attitudes is having low levels of support for gender equity [10]. The content and volume of information available regarding men's attitudes towards domestic violence and the characteristics that influence the propensity to behave violently in rural Upper Egypt are not sufficient to eliminate this problem, nor are they able to challenge community's beliefs and assumptions. As a result, we need to highlight men's role through exploring how they perceive domestic violence in order to develop strategies to stop the violence and help policy makers to find ways to involve men in the battle against home violence.

\subsection{Aim of the Study}

This research is only a small snapshot into believes of rural men towards home violence; how do they perceive it and what are the factors that affect their attitudinal direction either with or against it.

\subsection{Justification of the Study}

The overall impact of such violence is incalculable, as it not only directly affects individual victims but also their children, their families and friends, workplaces and communities. Domestic violence occurs in every socioeconomic level and at all ages of the community, where it is deeply rooted in communities showing inequality and power imbalances between men and women within the context of family's relationships. Attitudes and behaviors related to domestic violence are influenced by community norms [11].

Information regarding men's perceptions towards domestic violence and the propensity to behave violently in rural Upper Egypt is not sufficient to eliminate this problem, nor is it able to challenge community's beliefs and assumptions. As a result, we need to explore men's attitudes, beliefs and behaviors towards domestic violence in order to shape a tailored intervention to reduce the violence and help policy makers to find ways to involve men 
in the battle against home violence which has been a significant concern of both national and international community. Most Studies on domestic violence focus on women, and rarely providing information about possible perpetrator who are men.

\section{Subjects and Methods}

A cross-sectional community-based study was conducted in a rural area in Minia governorate that was chosen by a multistage random sample as Minia governorate was found to be divided into 9 districts from which Minia district was chosen randomly then Minia district was found to be divided into villages from which a village (Burgaia) was chosen randomly then a systematic random sample was taken from the village (the $1^{\text {st }}$ house was chosen randomly then every $3^{\text {rd }}$ house).

The sample size was calculated using EP Info version 2000. A total of 440 males, aged 18 to 92 years were participated in this study.

Face-to-face interviewing was used for data collection which was carried out by two interviewers who were previously trained by the investigators to be able to manage the specific challenges and difficulties encountered in studies on violence.

The study was conducted in the period from May to July, 2015. A pilot study was performed and the questionnaire was further validated through a review panel process where each item was considered for appropriateness.

Men's perception of domestic violence was measured from their responses to interview-administered structured questionnaire including questions as: whether or not they agree that a husband is justified to beat his wife when the wife does not cook well the food, argues with him, goes out without telling him, neglects the children, etc. Violence supportive attitudes do not openly endorse violence, but serve to support men's violence against women through views which justify, excuse, deny and minimize violence.

\subsection{What Is a Gender Equity Score (GES)?}

The 2006 Victorian Survey identified that the strongest predictor for holding violence-supportive views about violence against women was an individual's gender equity score [10]. This gender equity score or GES was constructed by asking respondents a series of attitudinal statements about women and their role in society. As with the 2006 Victorian Survey, the 2009 National Survey asked participants to respond to the same series of attitudinal statements relating to gender equity adapted from [11]. Responses to these statements were based on a likert scale where 1 = "strongly agree" and 5 = "strongly disagree". The questions were:

1) On the whole, men make better political leaders than women.

2) When jobs are scarce men should have more right to a job than women.

3) A university education is more important for a boy than a girl.

4) A woman has to have children to be fulfilled.

5) It's OK for a woman to have a child as a single parent and not want a stable relationship with a man (reversed scored).

In the 2009 survey additional three statements were included:

6) Discrimination against women is no longer a problem in the workplace.

7) Men should take control in relationships and be the head of the household.

8) Women prefer a man to be in charge of the relationship.

The gender equity scale and associated scores were calculated and summed to give a score out of 100 . Participants were required to respond to eight statements on a scale of 1 (strongly agree) to 5 (strongly disagree).

The eight statements were summed to give the respondent a score out of 40 . The score was then multiplied by 2.5 to give the respondent a score out of 100 . The score out of 100 was then categorized as "high GES" $(>90)$, "medium GES" (75 - 90) or "low GES" (<75).

Those who scored closest to 100 gave answers to the statements which indicated they supported gender equity - women should not only have equal rights and opportunities but be treated fairly and justly in the distribution of benefits and responsibilities between women and men. Those who scored lower on the gender equity scale expressed views that indicated less support for women being treated equally and fairly.

This research used the Gender Equity Scale [12]. 


\subsection{Statistical Analysis}

The Statistical Program SPSS for windows version 20 had been used in data analysis. For multivariate analyses the dependent variables were dichotomized into experience of violence as opposed to no experience of violence. Risk ratios were estimated by odds ratios (OR). Statistical significance was set at $\mathrm{p}<0.05$.

\subsection{Ethical Considerations}

The World Health Organization has issued guidelines for violence research and these were strictly followed. Interviews were held in strict privacy, mainly in the respondents' homes, with no one able to overhear the conversation. The participants were informed about their possibility to withdraw at any point during the research phase and gave written informed consent to participate. The study protocol had been approved by the standard ethics of Minia University ethical committee for human experimentation.

\section{Results}

This study included 440 male participants; whose ages ranged from 17 to 92 years with mean $(40.8 \pm 12.7)$.

In all, 90.5\% of respondents' scores felt within the low range of support for gender equity, $8.6 \%$ felt within the medium range of support. A majority of males reported low support for gender equity, and a smaller proportion of males reported high support for gender equity.

As shown from Table 1, nearly two thirds (69\%) of males practiced violence against their wives, $63.9 \%$ of this violence was physical, $26 \%$ was emotional and $10.1 \%$ was sexual.

Table 2 showed that $75 \%$ of men with high GES reported that violence is unnecessary compared to $33.4 \%$ of those with low GES $(\mathrm{P}=0.01)$.

Results from the multivariate logistic regression (Table 3) showed that secondary and university education $(\mathrm{OR}=2.7$ and 2.9 respectively), GES Score $(\mathrm{OR}=3.5)$ and working status $(\mathrm{OR}=2.7)$ were all significant risk factors for having self-reported perpetrating physical violence against a partner.

Figure 1 was divided into 2 parts to enhance visual clarity. It showed that, $66.1 \%$ of males agreed that women sometimes need to be "disciplined" from their husbands, 70.9\% agreed that men have the right to request the

Table 1. Distribution of participated men according to their practiced violence, Rural Minia, 2015.

\begin{tabular}{|c|c|c|}
\hline Characteristic & No. & $\%$ \\
\hline \multicolumn{3}{|l|}{ Practice of violence against wife $(n=429)$} \\
\hline Yes & 296 & 69 \\
\hline No & 133 & 31 \\
\hline \multicolumn{3}{|l|}{ Types of violence against wife $(n=296)$} \\
\hline Physical & 189 & 63.9 \\
\hline Sexual & 30 & 10.1 \\
\hline Emotional & 77 & 26 \\
\hline \multicolumn{3}{|l|}{ Causes of violence against wife $(n=296)$} \\
\hline The lack of attention \& care to the children & 133 & 44.9 \\
\hline Going out to work & 8 & 2.7 \\
\hline Lack of attention to husband & 116 & 39.2 \\
\hline Frequent outing of the house & 33 & 11.1 \\
\hline Others (mother in law) & 6 & 2.00 \\
\hline
\end{tabular}


Table 2. The relation between opinion of men towards existence of domestic violence within families and gender equity score (GES), Rural Minia, 2015.

\begin{tabular}{ccccc}
\hline $\begin{array}{c}\text { Men's opinion toward } \\
\text { domestic violence }\end{array}$ & Low GES & Medium GES & High GES & P-value \\
\cline { 2 - 4 } & $\mathrm{N}=398$ & $\mathrm{~N}=38$ & $\mathrm{~N}=4$ & \\
\hline Needed at all times & $29(7.9 \%)$ & $1(2.6 \%)$ & 0 & \\
Needed but not always & $236(59.3 \%)$ & $15(39.5 \%)$ & $1(25 \%)$ & $0.01^{*}$ \\
Un necessary & $133(33.4 \%)$ & $22(57.9 \%)$ & $3(75 \%)$ & \\
\hline
\end{tabular}

*Statistically significant.

Table 3. Multivariate logistic regression of correlates of lifetime physical violence perpetration against a partner, $(n=440)$, Rural Minia, 2015.

\begin{tabular}{lccc}
\hline \multicolumn{1}{c}{ Variable } & Odds ratio & $95 \%$ CI & P \\
\hline Period of marriage (mean) & 1.2 & $0.91-1.6$ & 0.2 \\
Education & - & & \\
No schooling or primary (ref) & 2.9 & $1.7-5.9$ & $0.001^{*}$ \\
Secondary & 2.7 & $1.2-6.1$ & $0.01^{*}$ \\
Above secondary & 0.91 & $0.82-1.02$ & 0.1 \\
Crowding index (mean) & & & \\
Income & - & & 0.1 \\
Low income (ref) & 0.30 & $0.05-1.5$ & 0.5 \\
Mid-low & 0.65 & $0.15-2.5$ & 0.1 \\
Mid-high & 0.30 & $0.06-13$ & \\
Highest &
\end{tabular}

Age groups:

Younger age group: <35 (ref)

Middle ages $35<55$

Old age: $>55$

0.59

$0.2-1.6$

GES score

Residence (rural )

Urban (ref)

Rural

Occupation

Not working (ref)

Working 

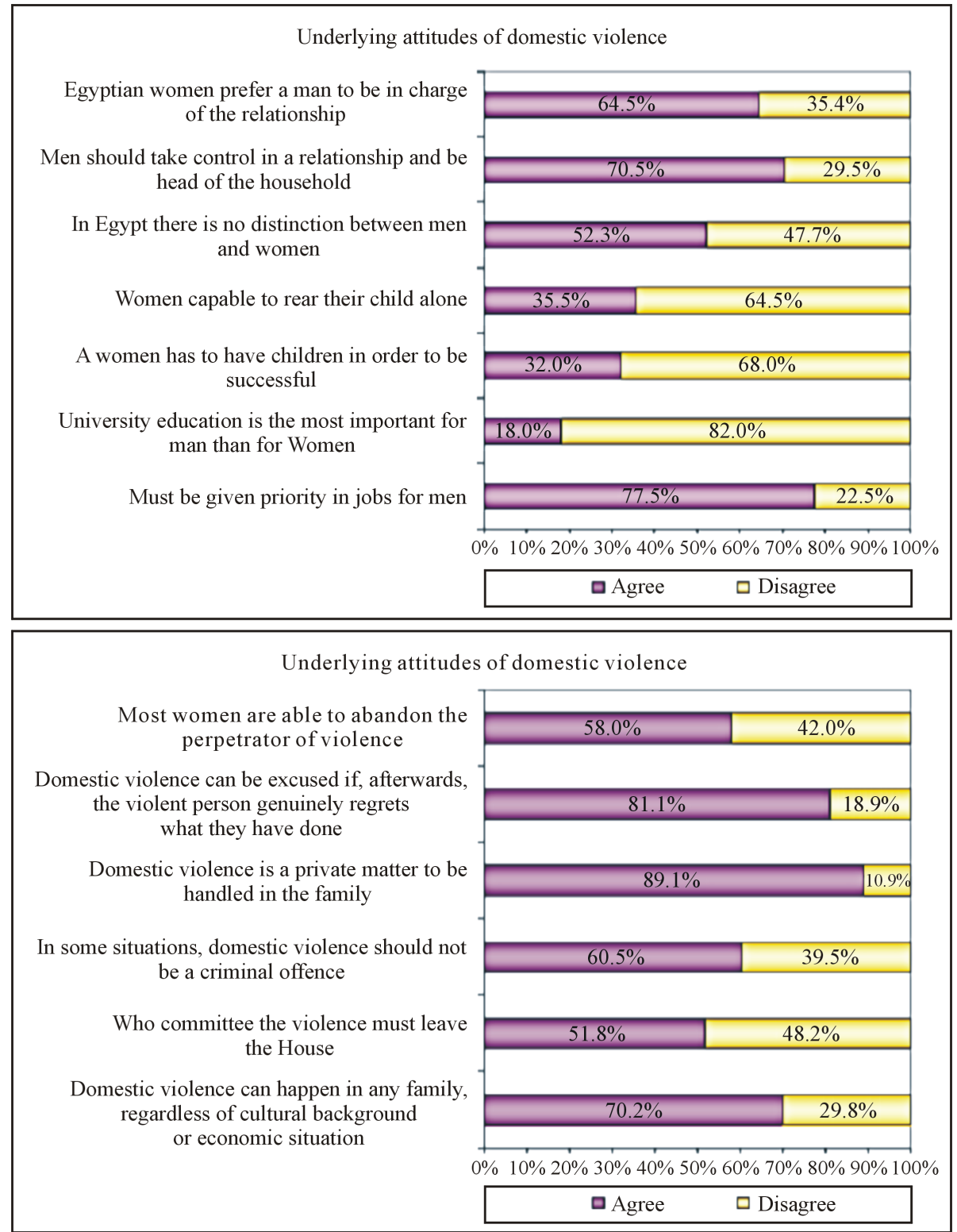

Figure 1. Men’s attitudes towards domestic violence, Rural Minia, 2015.

cohabitation of their wives when they want it. $91.1 \%$ agreed that the man is the most capable of the leadership than women, $82 \%$ of participant males disagreed that university education was important only for males than females, and $77.5 \%$ of them agreed that jobs must be given as a priority to males, $70.2 \%$ agreed that domestic violence happens in every house, whatever level, $68 \%$ disagreed that female reproduction is the indicator for her success and $64.5 \%$ disagreed that women capable to rear their children alone.

\section{Discussion}

As shown from this study, 90.5\% of respondents' scores fell within the low range of support for gender equity, 8.6\% fell within the medium range of support which not in agreement with what was reported by Alberta council of women's shelters (ACWS), 2012 who studied men's attitudes and behaviors toward violence against women and found that high gender equity score represented $18 \%$ of the studied sample compared to $48 \%$ medium score and $34 \%$ low score, this disagreement can be explained by the difference in demographics between 
the study participants [13].

The study found that participants who reported that domestic violence was needed but not always were $57.3 \%$, $6.8 \%$ reported that it was needed at all time and only $35.9 \%$ reported it was unnecessary, which was in agreement with Clark and Casey, 2012 who studied male attitudes regarding domestic and sexual violence and found that $56 \%$ of the studied males saw that domestic violence was somewhat common [14].

WHO 2009 in their study of promoting gender equality to prevent violence against women, they found that 52\% of the respondents had negative attitude towards an intimate partner. The study showed that $66.1 \%$ of males agreed that women sometimes need to "discipline" from their husbands, $70.9 \%$ agreed that men have the right to request the cohabitation of their wives when they want it. 91.1\% agreed that the man is the most capable of the leadership than women, 77.5\% agreed that men must be given priority for jobs [15].

This was in agreement with Qayyum, 2013 who studied domestic violence against women and men's perception in Districts of Pakistan and found that the majority of men linked manhood to authority, power and honor, and saw themselves as being superior to women who is supposed to be confined within the four walls [16].

Previous evidence had shown that in many countries use of physical violence was normatively accepted as a way of punishing a woman for the mistakes she has performed [17].

The study revealed that secondary and university education, GES Score and working were all significant risk factors for having self-reported perpetrating physical violence against a partner, having a higher level of education did not protect women against physical violence in rural areas, as those women with less than a primary education were less likely to experience violence compared to those with a primary education. This finding in rural areas could add to the dialogue on the curvilinear relationships between education and abuse [18]-[20], thereby supporting the argument that education may indeed increase the risk of abuse among women [21]. One plausible explanation of this finding in rural areas could be that many people still believe and practice traditions that could put a woman at even higher risk of physical violence. Fleming et al., 2015 found that men's GEM scores and employed men were also significantly correlated with violence perpetration [22].

Other prior studies had also noted the importance of financial viability in families with domestic violence [23] [24]. A possible explanation for this might be that many victims believed they should remain in the abusive relationship because primarily they were highly dependent on their husband's source of income. Indeed, some women may also have feelings of incompetence, lower self-esteem and lack of confidence to start hunting for a job.

\section{Conclusions and Recommendations}

- There is a tendency to describe this community as abusive, where the majority of the participants in this rural community perceived domestic violence as justified, and even practiced by almost all (91\%) of them in real life. There is window of opportunity which lies in the rejection by nearly two-thirds of participants of genderbased-discrimination.

- There is a need for development of a relevant and culturally sensitive domestic violence education/prevention program in rural Egypt. Health care staff at all levels is in need of training in how to address victimized persons and availability of free counseling clinics.

- Staff at health centers and health posts needs counseling skills and training in how to pose sensitive questions on violence to feel confident in handling complicated situations.

- Social, political, religious, and other leaders in speaking out against violence against women could form support groups for counseling.

- Media has a role to play in creating a debate on this topic.

- The need to develop, implement and evaluate programmes aimed at primary prevention of domestic violence.

\section{Acknowledgements}

The authors would like to thank all participants in the study.

\section{Conflicts of Interest}

The authors declare that there are no competing interests. 


\section{References}

[1] World Health Organization (2009) http://www.who.int/topics/violence/en/

[2] Ellsberg, M., Henrica, A., Jansen, F.M., Heise, L., Watts, C. and Garcia-Moreno, C. (2008) Intimate Partner Violence and Women's Physical and Mental Health in the WHO Multicountry Study on Women's Health and Domestic Violence: An Observational Study. Lancet, 371, 1165-1172. http://dx.doi.org/10.1016/S0140-6736(08)60522-X

[3] Home Office (2013) Extended Definition of Domestic Violence Takes Effect. https://www.gov.uk/government/news/extended-definition-of-domestic-violence-takes-effect

[4] FBI (2006) Crime in the United States. http://www.fbi.gov/ucr/05cius/about/offense_definitions.html

[5] Ellsberg, M. and Heise, L. (2005) Researching Violence against Women: A Practical Guide for Researchers and Activists. World Health Organization, Washington DC.

[6] Douki, S., Nacef, F., Belhadj, A., Bouasker, A. and Ghachem, R. (2003) Violence against Women in Arab and Islamic Countries. Arah Women Mental Health, 6, 165-171. http://dx.doi.org/10.1007/s00737-003-0170-x

[7] Zakar, R., Zakar, M.Z. and Kraemer, A. (2013) Men's Beliefs and Attitudes toward Intimate Partner Violence against Women in Pakistan. Violence against Women, 19, 246-268. http://dx.doi.org/10.1177/1077801213478028

[8] Marcus, G. and Braaf, R. (2007) Domestic and Family Violence Studies, Survey and Statistics: Pointers to Policy and Practice. Stakeholder Paper 1, Australian Domestic and Family Violence Clearinghouse, Sydney. http://www.adfvc.unsw.edu.au/PDF\%20files/Stakeholderpaper 1.pdf

[9] Flood, M. and Fergus, L. (2008) An Assault on Our Future: The Impact of Violence on Young People and Their Relationships. White Ribbon Foundation, Sydney.

http://www.whiteribbon.org.au/uploads/media/Research series/An assault on our future FULL Flood Fergus 201 $\underline{0 . p d f}$

[10] Taylor, N. and Mouzos, J. (2006) Community Attitudes to Violence against Women Survey 2006. Two Steps Forward, One Step Back: Community Attitudes to Violence against Women. VicHealth, Melbourne. http://aic.gov.au/publications/current\%20series/cfi/121-140/cfi138.html

[11] Inglehart and Norris (2003) Rising Tide Gender Equality and Cultural Change around the World. http://www.hse.ru/data/2013/02/20/1306830406/Inglehart\&Norris_Rising\%20Tide.pdf

[12] McGregor, K. (2009) National Community Attitudes towards Violence against Women Survey. A Full Technical Report, Australian Institute of Criminology, Canberra.

[13] ACWS (2012) Men's Attitudes and Behaviors toward Violence against Women. https://www.acws.ca/.../documents/PresentationACWSM

[14] Clark, R. and Casey, R. (2012) Male Attitudes regarding Domestic and Sexual Violence. Survey Data Report. www.vtnetwork.org/.../Male-Attitudes-Survey-FINAL-R

[15] World Health Organization (2009) WHO Multi-Country Study on Women's Health and Domestic Violence against Women. Summary Report of Initial Results on Prevalence, Health Outcomes and Women's Responses. World Health Organization, Geneva.

[16] Qayum, K. (2013) Domestic Violence against Women: Prevalence and Men’s Perception in PGRN Districts of Pakistan. http://news.rutgerswpf.nl/toolkit-for-men

[17] Jewkes, R. (2002) Intimate Partner Violence: Causes and Prevention. The Lancet, 359, 1423-1427. http://dx.doi.org/10.1016/S0140-6736(02)08357-5

[18] Hindin, M.J. and Adair, L.S. (2002) Who Is at Risk? Factors Associated with Intimate Partner Violence in the Philippines. Social Science and Medicine, 55, 1385-1399. http://dx.doi.org/10.1016/S0277-9536(01)00273-8

[19] Jewkes, R., Levin, J. and Penna-Kekana, L. (2002) Risk Factors for Domestic Violence: Findings from a South African Cross-Sectional Study. Social Science and Medicine, 5, 1603-1617. http://dx.doi.org/10.1016/S0277-9536(01)00294-5

[20] Karamagi, C.A., Tumwine, J.K., Tylleskar, T. and Heggenhougen, K. (2006) Intimate Partner Violence against Women in Eastern Uganda: Implications for HIV Prevention. BMC Public Health, 6, 284. http://dx.doi.org/10.1186/1471-2458-6-284

[21] Benta, A.A., Elijah, O.O., Da Kysha, M. and Crystal, N. (2012) Association between Education and Domestic Violence among Women Being Offered an HIV Test in Urban and Rural Areas in Kenya. Journal of Interpersonal Violence, 7, 2022-2038.

[22] Fleming, P., McCleary-Sills, J., Morton, M., Levtov, R., Heilman, B. and Barker, G. (2015) Risk Factors for Men’s Lifetime Perpetration of Physical Violence against Intimate Partners: Results from the International Men and Gender Equality Survey (IMAGES) in Eight Countries. PLoS ONE, 10, e0118639. http://dx.doi.org/10.1371/journal.pone.0118639 
[23] Adams, A.E. (2011) Measuring the Effects of Domestic Violence on Women’s Financial Well-Being. CFS Issue Brief 2011, 5.6, Center for Financial Security, University of Wisconsin-Madison, Madison.

[24] O’Rourke, C. (2010) Financial Capability and Domestic Violence Prevention. CFS Issue Brief 2010, 10.1, Center for Financial Security, University of Wisconsin-Madison, Madison. 